\title{
Simple Half-Wave Dipole Antenna Analysis for Wireless Applications by CST Microwave Studio
}

\author{
Mohammad Tareq* \\ Asst. Professor, \\ Dept. of EETE, \\ Dhaka International \\ University (DIU), \\ 66-Green Road, \\ Dhaka-1205, Bangladesh
}

\author{
Dewan Ashraful \\ Alam \\ Programmer, Election \\ Commission Secretariat, \\ Sher-E-Bangla Nagar, \\ Dhaka-1207, \\ Bangladesh
}

\author{
Mazidul Islam \\ Lecturer, Dept. of EETE, \\ Dhaka International \\ University (DIU), \\ 66, Green Road, Dhaka- \\ 1205, Bangladesh
}

\author{
Razin Ahmed \\ Lecturer, Dept. of EEE, \\ International University \\ of Business Agriculture \\ and Technology \\ (IUBAT), \\ Dhaka-1230, \\ Bangladesh
}

\begin{abstract}
In this paper, a simple half-wave dipole antenna has been designed and analyzed for wireless applications. Resonant frequency for the dipole antenna was $5 \mathrm{GHz}$ and as a simulation tool CST Microwave Studio (MWS) has been used. After that the return loss curve, the VSWR and the farfield radiation patterns of the half-wave dipole antenna have been observed.
\end{abstract}

\section{Keywords}

Dipole Antenna, CST MWS, Far-field radiation

\section{INTRODUCTION}

Dipole antenna is very common practical wire antenna [1]. There are several types of dipole antennas such as hartzian dipole, half-wave dipole, small dipole [2] etc.

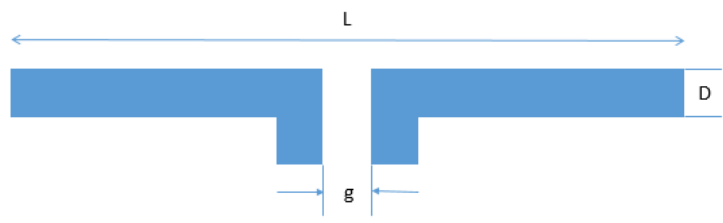

Fig. 1: Half-Wave Dipole Antenna

A general construction of a half-wave dipole antenna [3] has been shown in the Fig.1. There is a gap between two arms of half-wave dipole antenna for feeding purpose. Here $\mathrm{L}$ is the total length of the antenna, D is the thickness of antenna arm and $g$ is the feeding gap. Radiation resistance of the half-wave dipole is $73 \mathrm{Ohm}$ which matched with the line impedance [4].

\section{DESIGN PARAMETERS}

Dimension of an antenna changes based on the resonant frequency. As a resonant frequency $5 \mathrm{GHz}$ has been chosen. By taking this into consideration several antenna dimension have been calculated [5].

Resonant frequency, $f_{r}=5 \mathrm{GHz}$

Wavelength,

$\lambda=\frac{c}{f}=\left(3 \times 10^{11}\right) \div\left(5 \times 10^{9}\right)=60 \mathrm{~mm}$.

Length of half-wave dipole antenna,

$L=\frac{143}{f}=28.6 \mathrm{~mm}$
Feeding gap of the antenna,

$g=\frac{L}{200}=\frac{28.6}{200}=0.143 \mathrm{~mm} \ldots$

Radius of the wire,

$R=\frac{\lambda}{1000}=\frac{60}{1000}=0.06 \mathrm{~mm} \ldots$

From the first equation, wavelength has been calculated based on which length of the dipole antenna has been found from the second equation. Feeding gap and radius of the wire have been calculated from the equation no. 3 and 4 respectively.

All dimensions of the antenna are given in the Table 1.

Table 1: Design Parameters of the Antenna

\begin{tabular}{|c|c|c|}
\hline Parameter & Value & Unit \\
\hline Resonant Frequency $\left(\mathrm{f}_{\mathrm{r}}\right)$ & 5 & $\mathrm{GHz}$ \\
\hline Wavelength $(\lambda)$ & 60 & $\mathrm{~mm}$ \\
\hline Impedance & 73 & $\mathrm{Ohm}$ \\
\hline Length of the dipole $(\mathrm{L})$ & 28.6 & $\mathrm{~mm}$ \\
\hline Radius of the dipole $(\mathrm{R})$ & 0.06 & $\mathrm{~mm}$ \\
\hline
\end{tabular}

\section{SIMULATIONS AND RESULTS}

\subsection{Simulations}

According to the design parameters a half-wave dipole antenna has been designed in CST MWS. In the Fig. 2 designed half-wave dipole antenna has been shown.

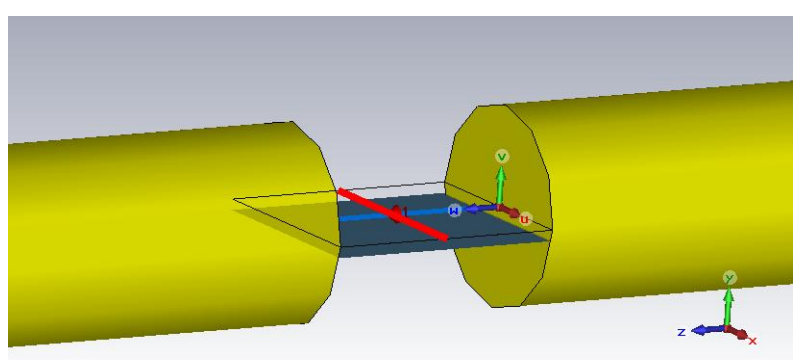

Fig. 2: Designed Half-Wave Dipole Antenna

For the simulation purpose the ranges of frequencies have been chosen from $4 \mathrm{GHz}$ to $6 \mathrm{GHz}$.

For making the simulation fast and more accurate global mesh properties have been optimized. As antenna copper (annealed) 
has been used and between the two antenna arms a sheet has been selected.

\subsection{Results}

After the simulation return loss has been observed. Return loss curve has been shown in the Fig.3.

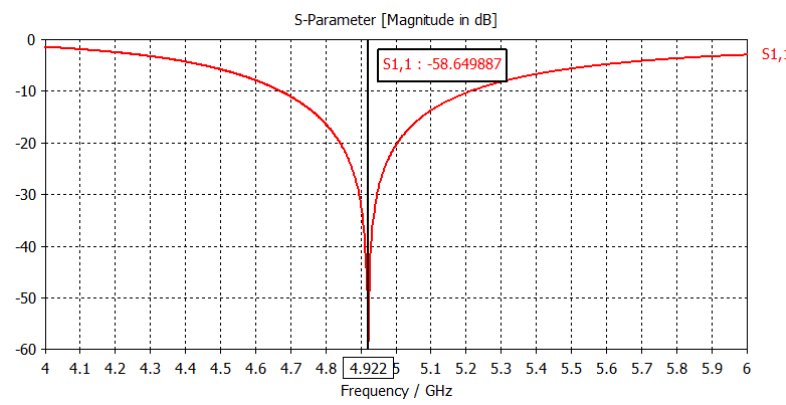

Fig. 3: Return Loss Curve for the designed Half-Wave Dipole Antenna

From the Fig. 2 authors have found that the antenna is resonating at $4.992 \mathrm{GHz}$. Moreover, the value of return loss has been found as $-58.65 \mathrm{~dB}$ (approx.).

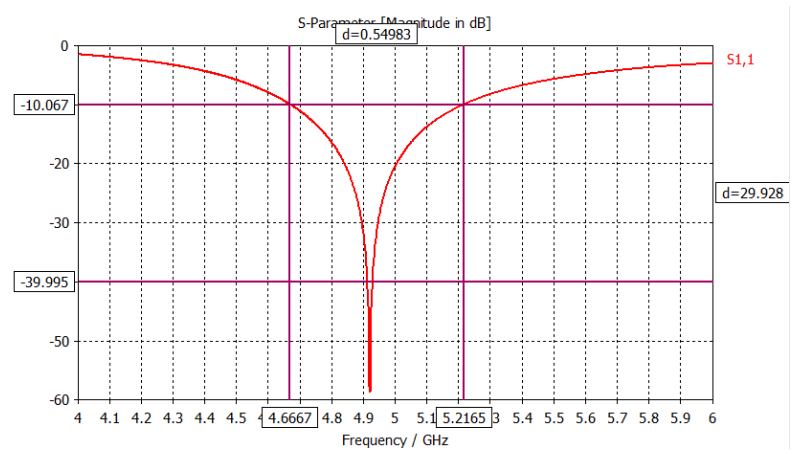

Fig. 4: Bandwidth Curve for the designed Half-Wave Dipole Antenna

Bandwidth of the antenna has shown in the Fig. 4. Bandwidth of the designed antenna has found as $0.54983 \mathrm{GHz}$. Ranges of frequency at $-10 \mathrm{~dB}$ are $4.6667 \mathrm{GHz}$ and $5.2165 \mathrm{GHz}$.

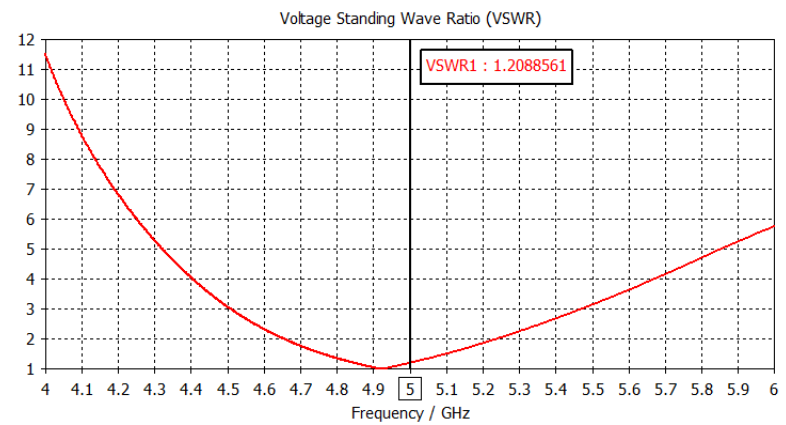

Fig. 5: VSWR Plot of the designed Half-Wave Dipole Antenna

VSWR curve has shown in the Fig. 5. Authors have found it was 1.2 at the resonant frequency $5 \mathrm{GHz}$.

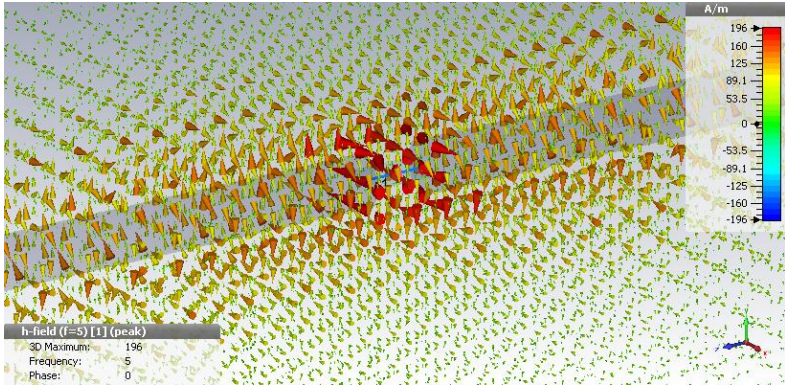

Fig. 6: H-field Distribution of the designed Half-Wave Dipole Antenna

Magnetic field density has shown in the Fig. 6.

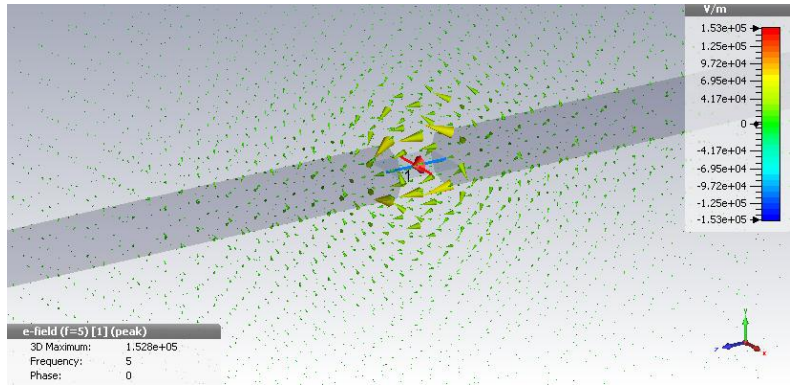

Fig. 7: E-field Distribution of the designed Half-Wave Dipole Antenna

Electric field distribution has shown in the Fig. 7.

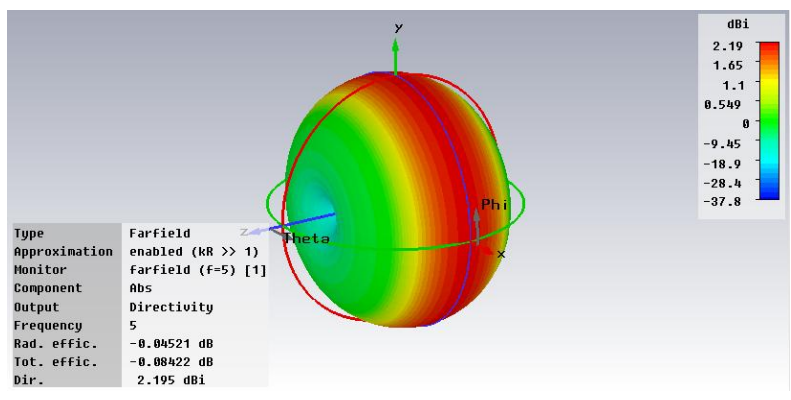

Fig. 8: 3-D Far-Field Radiation Pattern for Directivity of Designed Half-Wave Dipole Antenna

Far-field radiation [6] pattern has been shown in the Fig. 8. Directivity has found as $2.195 \mathrm{dBi}$. Obtained directivity was almost identical to the theoretical ones [7]. Red color shows the maximum radiation.

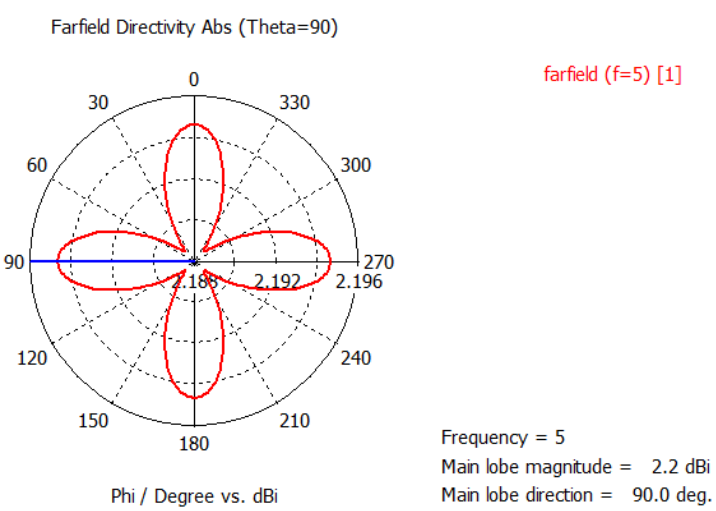

Fig. 9: Polar Plot for Azimuthal Angle of the Designed Half-Wave Dipole Antenna 
Polar plot for azimuthal angle has shown in the Fig. 9.

Farfield Directivity Abs (Phi=90)

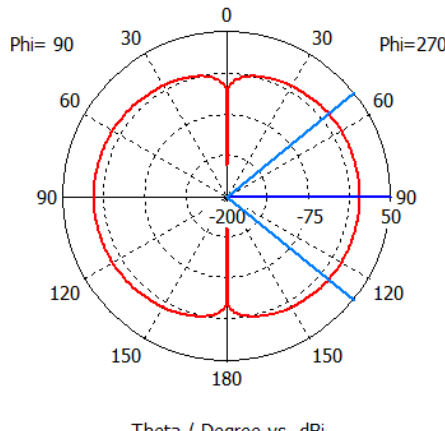

farfield $(f=5)[1]$

Frequency $=5$

Main lobe magnitude $=2.2 \mathrm{dBi}$ Main lobe direction $=90.0 \mathrm{deg}$. Angular width $(3 \mathrm{~dB})=77.9 \mathrm{deg}$

Fig. 9: Polar Plot for Elevation Angle of the Designed Half-Wave Dipole Antenna

Polar plot for elevation angle has shown in the Fig. 9.

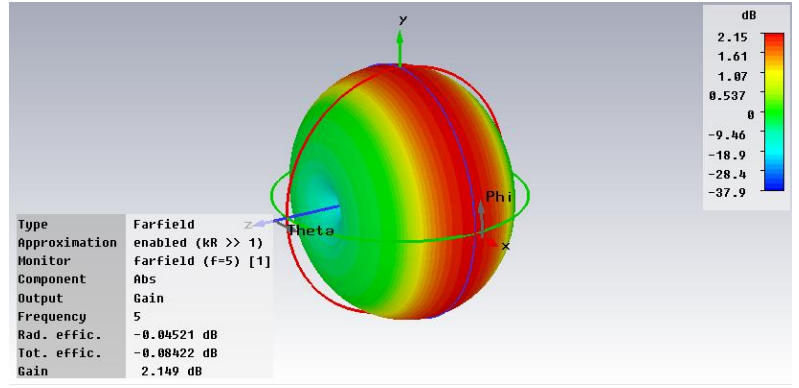

Fig. 10: Far-field Radiation Pattern for Gain of the Designed Half-Wave Dipole Antenna

Gain has found as $2.149 \mathrm{~dB}$ from the simulation which has shown in the Fig. 10.

Summary of the simulated results are given in the Table 2 .

Table 2: Simulated Results of the Designed Antenna

\begin{tabular}{|c|c|c|}
\hline Parameter & Value & Unit \\
\hline Resonant Frequency $\left(\mathrm{f}_{\mathrm{r}}\right)$ & 4.922 & $\mathrm{GHz}$ \\
\hline Bandwidth & 0.54983 & $\mathrm{GHz}$ \\
\hline Directivity & 2.195 & $\mathrm{dBi}$ \\
\hline Gain & 2.149 & $\mathrm{~dB}$ \\
\hline Return Loss & -58.6498 & $\mathrm{~dB}$ \\
\hline
\end{tabular}

\section{CONCLUSIONS}

Main objective of this paper was to observe the several antenna characteristics for popular wire antenna. As a popular practical antenna half-wave dipole antenna was selected. Obtained results were acceptable for practical implementation of this types of antennas. As a simulation tool CST Microwave Studio was used which ease the simulation. Obtained resonant frequency $(4.992 \mathrm{GHz})$ was lesser than target frequency $(5 \mathrm{GHz})$ which is acceptable. Return loss obtained as $-58.6498 \mathrm{~dB}$ which shows the characteristic of reflection coefficient. Bandwidth was observed as almost 550 $\mathrm{MHz}$ which is good enough to cover various wireless applications. There are few scopes to improve the results by optimizing several parameters which might be fruitful for researchers. Author would like to work on these in future.

\section{REFERENCES}

[1] Balanis, Constantine A., "Antenna Theory Analysis and Design", John Wiley \& Sons, $3^{\text {rd }}$ Edition, USA (2005), pg. 151

[2] Ramo, Simon, Whinnery, John R., Duzer, Theodore Van, "Fields and Waves in Communication Electronics", John Wiley \& Sons, $3^{\text {rd }}$ Edition, Canada (1994)

[3] Saunders, Simon R., Zavala, Alezandro Aragon, "Antennas and Propagation for Wireless Communication Systems", John Wiley \& Sons, $2^{\text {nd }}$ Edition, England (2007), pg. 73

[4] Balanis, Constantine A., "Antenna Theory Analysis and Design", John Wiley \& Sons, $3^{\text {rd }}$ Edition, USA (2005), pg. 182

[5] Parminder Singh, Ankita Sharma, Neha Uniyal,Richa Kala, "Half-Wave Dipole Antenna for GSM Applications", International Journal of Advanced Computer Research (ISSN (print): 2249-7277 ISSN (online): 2277-7970), Volume-2 Number-4 Issue-6 December-2012

[6] Balanis, Constantine A., "Antenna Theory Analysis and Design", John Wiley \& Sons, $3^{\text {rd }}$ Edition, USA (2005), pg. 34-35

[7] Saunders, Simon R., Zavala, Alezandro Aragon, "Antennas and Propagation for Wireless Communication Systems", John Wiley \& Sons, $2^{\text {nd }}$ Edition, England (2007), pg. 77 